\title{
Converging mediators from immune and trophic pathways to identify Parkinson disease dementia
}

\section{OPEN}

Lih-Fen Lue, $\mathrm{PhD}$

Christopher T. Schmitz, BS

Noelle L. Snyder, MS

Kewei Chen, PhD

Douglas G. Walker, PhD

Kathryn J. Davis, BA

Christine Belden, PsyD

John N. Caviness, MD

Erika Driver-Dunckley, MD

Charles H. Adler, MD, $\mathrm{PhD}$

Marwan N. Sabbagh, MD Holly A. Shill, MD

Correspondence to Dr. Lue:

lih-fen.lue@asu.edu

\section{ABSTRACT}

Objective: To identify a panel of peripheral inflammatory/immune mediators that could discriminate Parkinson disease with dementia (PDD) from Parkinson disease (PD) without dementia.

Methods: Plasma samples from 52 patients with PD and 22 patients with PDD were prepared from freshly collected blood following an institutional review board-approved protocol. A total of 160 proteins were measured using a multiplex antibody array. Plasma $\alpha$-synuclein levels were analyzed by an electrochemiluminescence immunoassay. The main objective of the statistical analyses was to identify PDD discriminants using the plasma protein profile alone or in combination with age.

Results: The PD and PDD groups differed significantly in cognitive measurements (Mini-Mental State Examination, Auditory Verbal Learning Test-A7, and Clinical Dementia Rating) and age. The age-adjusted levels of thymus and activation-regulated chemokine (TARC) and plateletderived growth factor (PDGF)-AA were significantly different between disease groups. The levels of plasma $\alpha$-synuclein significantly correlated with 26 proteins; among them, PDGF-BB, TARC, PDGF-AA, and epidermal growth factor were the highest. Linear discriminant analysis with leaveone-out cross-validation identified a 14-protein panel with age as discriminants of PDD $196 \%$ sensitivity, 89\% specificity, area under the curve $=0.9615)$.

Conclusions: We showed that multiple proteins that are mediators of growth/trophic and immune response-related pathways had discriminatory power for identifying PDD in patients with PD. Validation of this discovery-based study in longitudinal population-based studies is warranted.

Classification of evidence: This study provides Class III evidence that a 14-protein panel plasma assay combined with age has a sensitivity of $96 \%$ and a specificity of $89 \%$ for PDD. Neurol Neuroimmunol Neuroinflamm 2016;3:e193; doi: 10.1212/NXI.0000000000000193

\section{GLOSSARY}

AUC $=$ area under the curve; ASAND $=$ Arizona Study of Aging and Neurodegenerative Disorders; $\mathbf{A V L T - A 7}=$ Auditory Verbal Learning Test-A7; BLC = B lymphocyte chemoattractant; BMP = bone morphogenetic protein; $\mathbf{B T C}=$ betacellulin; $\mathbf{C C L}=$ chemokine (C-C motif) ligand; CD14 = cluster of differentiation 14; CDR = Clinical Dementia Rating; CEACAM-1 = carcinoembryonic antigen cell adhesion molecule-1; CXCL = chemokine (C-X-C motif) ligand; DRS-2 = Dementia Rating Scale-2; DSM-IV = Diagnostic and Statistical Manual of Mental Disorders, 4th edition; EGF = epidermal growth factor; ENA-78 = epithelial-derived neutrophil-activating peptide 78; ErbB3 = receptor tyrosine-protein kinase erbB-3; FDR = false discovery rate; FGF-4 = fibroblast growth factor-4; GDNF = flial cell-derived neurotrophic factor; GITR = glucocorticoid-induced TNFR-related protein; GRO = growth-regulated alpha protein; HBEGF = heparin-binding EGF-like growth factor; IGF-1 = insulin-like growth factor1; IGFBP = insulin like growth factor binding protein; IL = interleukin; LDA = linear discriminant analysis; LIGHT = TNF ligand superfamily member 14; MIG = monokine induced by interferon-gamma; MMSE = Mini-Mental State Examination; NGF = nerve growth factor; NT = neurotrophin; PD = Parkinson disease; PDD = Parkinson disease with dementia; PDGF = platelet-derived growth factor; PIGF = placenta growth factor; QEEG = quantitative EEG; RANTES = regulated on activation, normal T cell expressed and secreted; ROC = receiver operating characteristic; $\mathbf{S C F}=$ stem cell factor; TARC $=$ thymus and activationregulated chemokine; TGF- $\boldsymbol{\beta} \mathbf{3}=$ Transforming growth factor- $\beta-3$; TIMP-1 $=$ tissue inhibitor of metalloproteinases- 1 ; TNF $=$ tumor necrosis factor; $\mathbf{u P A R}=$ urokinase plasminogen activator receptor.

Progressive cognitive decline leading to dementia is a major nonmotor clinical feature frequently observed during the course of Parkinson disease (PD). The cognitive deficits affect the domains of attention, execution function, language, visuospatial functions, and memory in patterns distinguishable from Alzheimer disease. ${ }^{1,2}$ Patients with PD have a 4- to 6-fold greater incidence of

Authors' affiliations are listed at the end of the article.

Funding information and disclosures are provided at the end of the article. Go to Neurology.org/nn for full disclosure forms. The Article Processing Charge was paid by the authors.

This is an open access article distributed under the terms of the Creative Commons Attribution-NonCommercial-NoDerivatives License 4.0 (CC BY-NC-ND), which permits downloading and sharing the work provided it is properly cited. The work cannot be changed in any way or used commercially. 
dementia than normal controls. ${ }^{3,4}$ Studies that followed patients with PD for 8 or 20 years reported cumulative prevalence rates of dementia of $78 \%$ and $83 \%$, respectively. ${ }^{5,6}$ Having both dementia and motor dysfunctions increases mortality by 3.8 -fold. ${ }^{7}$ Dementia also decreases the quality of life for patients with PD while increasing financial and caregiving burdens. ${ }^{8-11}$

It is important to diagnose cognitive impairment at the earliest stage in order to improve the effectiveness of the limited treatment options. ${ }^{12-14}$ Because early symptoms are often underrecognized, it would be useful if cognition-associated blood biomarkers that discriminate PD with dementia (PDD) from PD could improve the accuracy of diagnosis. ${ }^{15}$ Peripheral inflammatory cytokines, chemokines, and growth factors have been investigated for their relationship with cognitive decline in patients with PD. ${ }^{16-20}$ Lower levels of epidermal growth factor (EGF) have been shown to correlate with poor cognitive performance and development of PDD in a separate cohort. ${ }^{16,18}$ Results of these studies support the potential of blood-based biomarkers for predicting cognitive dysfunction in patients with PD.

To identify further plasma proteins that may serve as discriminants for PDD, we used an unbiased biomarker discovery approach. ${ }^{21}$ The findings from a cohort of 52 patients with PD and 22 patients with PDD are reported here.

METHODS Classification of evidence. This study aimed to determine whether there is a specific panel of plasma immune and growth factors that distinguish PDD from PD. The study provides Class III evidence that a 14-protein panel plasma assay combined with age has a sensitivity of $96 \%$ and a specificity of $89 \%$ for PDD in a cohort of 52 patients with PD and 22 patients with PDD.

Participants. This cross-sectional study consisted of 52 patients with PD and 22 patients with PDD who were recruited at the Banner Sun Health Research Institute. Fifty-one of the patients with PD and 8 of patients with PDD were enrolled in the Arizona Study of Aging and Neurodegenerative Disorders (ASAND) (previously called Brain and Body Donation Program)..$^{22}$ One patient with PD and 14 patients with PDD were not enrolled in ASAND, but they received clinical diagnosis from the attending neurologists at the same clinical center as ASAND was operated.

Standard protocol approvals, registrations, and patient consents. The study was conducted according to the human subject study protocol (number 20111004) approved by Western Institutional Review Board (Puyallup, WA). Written informed consent was obtained from all participants.
Diagnosis. ASAND participants received annual movement, clinical, and neuropsychological assessments. ${ }^{22} \mathrm{PD}$ diagnosis is based on having 2 of 3 cardinal features of PD (resting tremor, bradykinesia, or rigidity), no obvious symptomatic causes, and documented response to dopaminergic medication. A large battery of neuropsychological tests is performed annually on the ASAND participants. These tests include the Mini-Mental State Examination (MMSE), Rey Auditory Verbal Learning Test-A7 (AVLT), Controlled Oral Word Association Test, Stroop Interference, Trails B, Wechsler Adult Intelligence Scale-III Digit Span, and Judgment of Line Orientation Test. Participants were classified as having PDD or PD by consensus conference among the clinical center movement disorder neurologist, behavioral neurologist, and neuropsychologists based on the Movement Disorder Society criteria for the diagnosis of PDD and the DSM-IV criteria for dementia. The present study excluded patients with PD who were diagnosed as having PD with mild cognitive impairment. ${ }^{23}$ The record of when PD and PDD were diagnosed was available in 18 patients with PDD. The duration of PD prior to diagnosis of PDD as well as the duration between PDD diagnosis and blood draw were calculated for these patients.

Blood sample collection. Approximately $16 \mathrm{~mL}$ of blood from each participant was collected into 2 ethylenediaminetetraacetic acid-coated tubes and processed within 30 minutes to obtain plasma by centrifugation at $1,500 \mathrm{~g}$ for 15 minutes, a standardized procedure according to the recommendations of the Parkinson's Progression Marker Initiative. ${ }^{24}$ Plasma samples were aliquoted into $250 \mu \mathrm{L}$ volume and stored at $-80^{\circ} \mathrm{C}$ until analysis. Aliquots were thawed and mixed gently prior to all of the assays. No genotype and gene mutation were determined in this study because DNA samples were not available.

Quantibody multiplex ELISA assays. The Quantibody Human Cytokine Array Q3000 (RayBiotech, Norcross, GA) was used to measure the concentrations of 160 cytokines, chemokines, receptors, and growth factors, with results calculated relative to the known concentrations of protein standards. The list of these proteins is available at the company's Web site (http://www.raybiotech.com/ quantibody-human-cytokine-array-3000.html). The arrays were constructed on glass slides spotted with 16 wells of an identical antibody panel with each antibody spotted in quadruplicate. The standard curves were generated from 6 to 8 diluted concentrations of standard proteins on each slide. The assay procedure followed the manufacturer's protocol. Lower limits of detection were determined using the lowest concentrations of standards that were at least 3 times above the background. Data output was analyzed with Quantibody Q-Analyzer software. The reproducibility of the assay determined by coefficient of variation is $<20 \%$.

$\boldsymbol{\alpha}$-Synuclein ELISA. The plasma $\alpha$-synuclein levels were measured by Human $\alpha$-Synuclein kit (Meso Scale Diagnostics, Rockville, MD) following the manufacturer's protocol. The assay was similar to conventional ELISAs except captured antigen was detected by the $\alpha$-synuclein antibody conjugated with electrochemiluminescent labels. The emitted electrosignals were read by a MESO QuickPlex SQ 120 plate reader (Meso Scale Diagnostics). The values of standard curves and protein concentrations in each replicate were calculated with Discovery Workbench Software provided by the manufacturer. The optimal dilution factor (1:40) was determined in a subset of the plasma samples before assaying the entire sample series.

Statistical analysis. The main goal of the statistical analysis was to identify those measures best able to distinguish PDD from PD. This was accomplished by using linear discriminant analysis (LDA) classification models. Levels of individual proteins were 
first examined for their capacity to separate PDD from PD using independent 2-sample Student $t$ tests with false discovery rate (FDR) for multiple comparison correction for the distinguishing power of each individual protein and without multiple comparison correction as a feature selection procedure to identify a discriminant protein panel before LDA. A second LDA was performed using automated stepwise selection of 161 proteins to determine the best protein panel.

In all LDA classification models, performance metrics of sensitivity and specificity, based on the optimal threshold, and the area under the receiver operating characteristic (ROC) curve (AUC) were compared using leave-one-out cross-validation. The AUC serves to evaluate overall model performance by taking into account both the true-positive rate, or sensitivity, and the false-positive rate at different confidence thresholds. ${ }^{24}$ In each model, we aimed to select a threshold corresponding to high sensitivity while maintaining an acceptable specificity, or true-negative rate, in order to accurately identify participants with dementia.

In addition to the primary purpose of identifying proteins able to distinguish PD and PDD, the strengths of pairwise Pearson correlations for those proteins included in each model were examined to explore possible interactions. Correlation analyses were also performed to determine the separate association of these proteins with age, $\alpha$-synuclein levels, disease duration, and scores assigned by neuropsychological assessment. The results were subjected to multiple comparison correction using FDR. To assess the relevance of the selected 14 protein discriminants, we examined the overall correlation of these proteins with cognitive measures such as MMSE, CDR, and AVLT-A7 using multivariable linear regression models. Statistical analyses were performed using the statistical package SPSS (version 22, IBM, Armonk, NY) with subsequent modeling and performance comparison completed in MATLAB (version R2014b, MathWorks, Natick, MA).

RESULTS Study cohort. Our study cohort consisted of 59 ASAND participants (51 with PD and 8 with PDD) and 15 non-ASAND participants (1 with PD and 14 with PDD) who received medical care from clinic neurologists at the study site. Although no neuropsychological tests were performed on the 14 patients with PDD, clinical criteria for diagnosis were consistent for all participants.

The demographic, movement, and neuropsychological features of the cohort are shown in table 1 . The PDD group was significantly older than the PD group $(p=0.019)$. There was no difference in the ratio of male to female participants between disease groups $(p=0.697)$. The PDD group had significantly lower AVLT-A7 and MMSE scores but higher CDR scores than the PD group. The Unified Parkinson's Disease Rating Scale scores were not significantly different between the PD and PDD groups ( $p=0.270$ ).

Using data from the 18 patients with PDD who had record of disease diagnosis, the mean \pm SE of the duration between diagnosis of PD and PDD was $10.2 \pm 1.38$ years and the mean \pm SE of the duration of dementia was $3.67 \pm 0.63$ years.

Protein levels by disease group. We determined the disease group differences in plasma levels of 161 proteins. Significant differences were detected in 12 proteins, including BMP-7, FGF-7, GDNF, IGFBP-1, Insulin, NT-4, PDGF-AA, PIGF, TARC, TGFb3, SCF, and uPAR. Further analysis indicated that age was a covariate of the protein levels, but not sex. Because participants with PD and participants with PDD differed in age, we then determined the disease group differences after adjusting for age. Only TARC and PDGF-AA levels remained significantly different between disease groups. The levels in the PDD group were higher than those in the PD group: $833.72 \pm$ $92.69 \mathrm{pm} / \mathrm{mL}$ in PD and 1,222.25 $\pm 144.74 \mathrm{pg} / \mathrm{mL}$ in PDD $(p=0.029)$ for TARC and 6,497.12 \pm $497.64 \mathrm{pg} / \mathrm{mL}$ in PD and 8,521.12 $\pm 777.06 \mathrm{pg} / \mathrm{mL}$ in PDD $(p=0.034)$ for PDGF-AA. However, the significance did not survive FDR correction.

\begin{tabular}{|c|c|c|c|}
\hline Demographic $^{a}$ & $\mathrm{PD}(\mathrm{n}=52)^{\mathrm{b}}$ & $\operatorname{PDD}(n=22)^{b}$ & $p$ Value $^{c}$ \\
\hline Age (52/22) & $73.1 \pm 1.27(47-87)$ & $78.4 \pm 1.59(63-91)$ & $0.019^{d}$ \\
\hline \multicolumn{4}{|l|}{ Sex } \\
\hline Male, n (\%) & 33 (63.5) & 15 (68.2) & 0.697 \\
\hline Female, $\mathrm{n}(\%)$ & 19 (36.5) & 7 (31.8) & \\
\hline Education, yr (47/7) & $15.7 \pm 0.406(8-23)$ & $15.3 \pm 0.944(12-20)$ & 0.739 \\
\hline UPDRS score $(44 / 5)$ & $21.0 \pm 2.02(0-54)$ & $36.0 \pm 11.7(6-74)$ & 0.270 \\
\hline MMSE score (51/8) & $27.96 \pm 0.284(21-30)$ & $20.3 \pm 1.81(15-29)$ & $0.004^{d}$ \\
\hline AVLT-A7 score (51/8) & $8.49 \pm 0.481(2-15)$ & $2.50 \pm 0.756(0-6)$ & $1.3 \mathrm{E}-5^{\mathrm{d}}$ \\
\hline Global CDR (51/8) & $0.049 \pm 0.0210(0-0.5)$ & $1.63 \pm 0.183(1-2)$ & $5.1 \mathrm{E}-5^{\mathrm{d}}$ \\
\hline
\end{tabular}

Abbreviations: AVLT-A7 = Auditory Verbal Learning Test-A7; CDR = Clinical Dementia Rating; MMSE = Mini-Mental State Examination; PD = Parkinson disease; PDD = Parkinson disease with dementia; UPDRS = Unified Parkinson's Disease Rating Scale.

${ }^{a}$ (No. patients with PD/no. patients with PDD) for each demographic.

${ }^{\mathrm{b}}$ Mean $\pm \mathrm{SE}$ (range) for continuous variables.

${ }^{c} p$ Value from $t$ test for continuous variables and $\chi^{2}$ test for categorical variables.

${ }^{\mathrm{d}}$ Significant at $\alpha=0.05$. 
Biochemical discriminants of PDD. To determine whether measures of a single protein or a combination of proteins might be useful for discriminating PDD from $\mathrm{PD}$, we performed the simple and conventional
LDA. The statistical steps and the findings of discriminant panels are shown in figure 1.

We first determined whether age-adjusted TARC and PDGF-AA levels could be used for disease

\section{Figure 1 Statistical models and discriminant panels that discriminated PDD from PD}

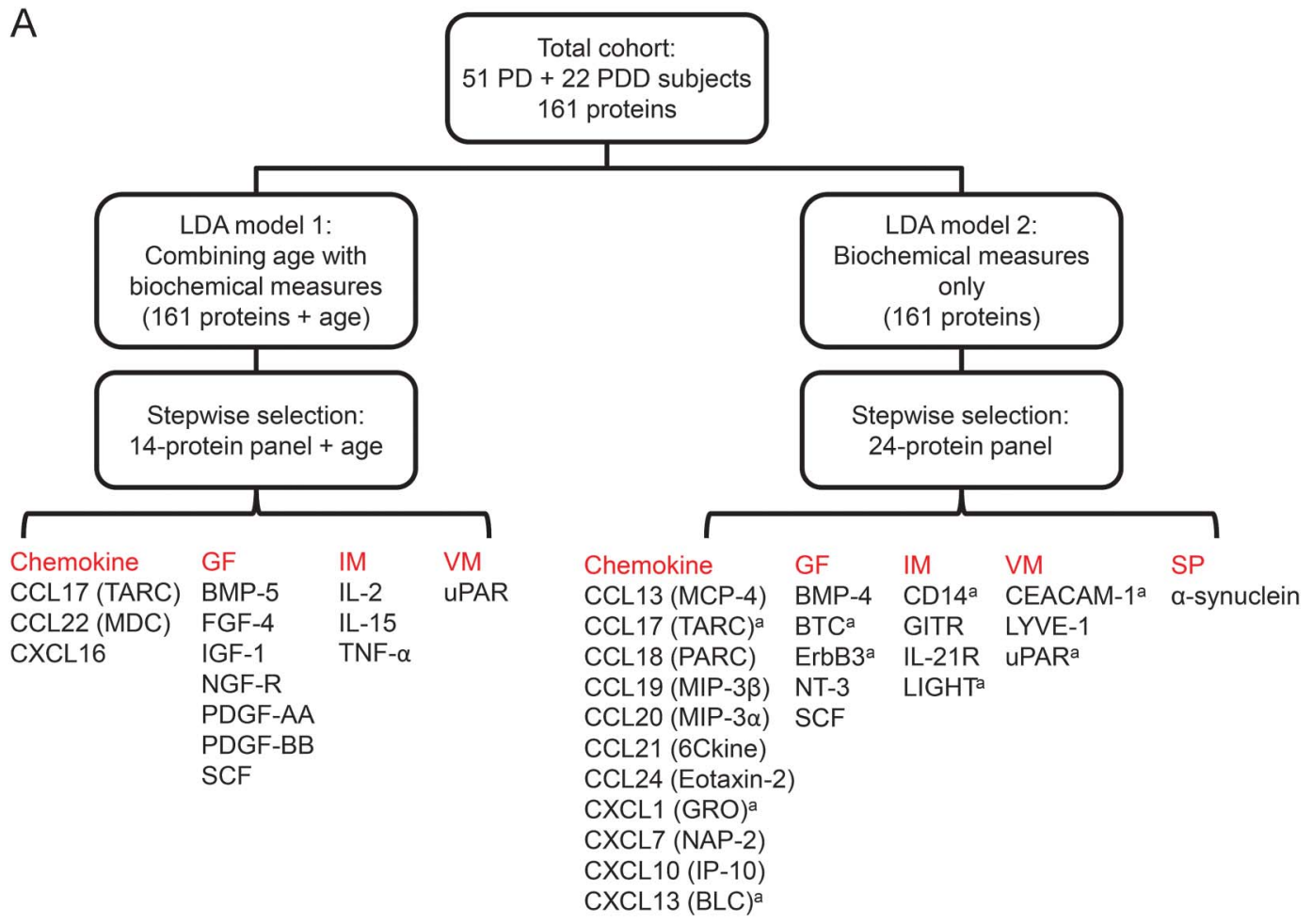

B

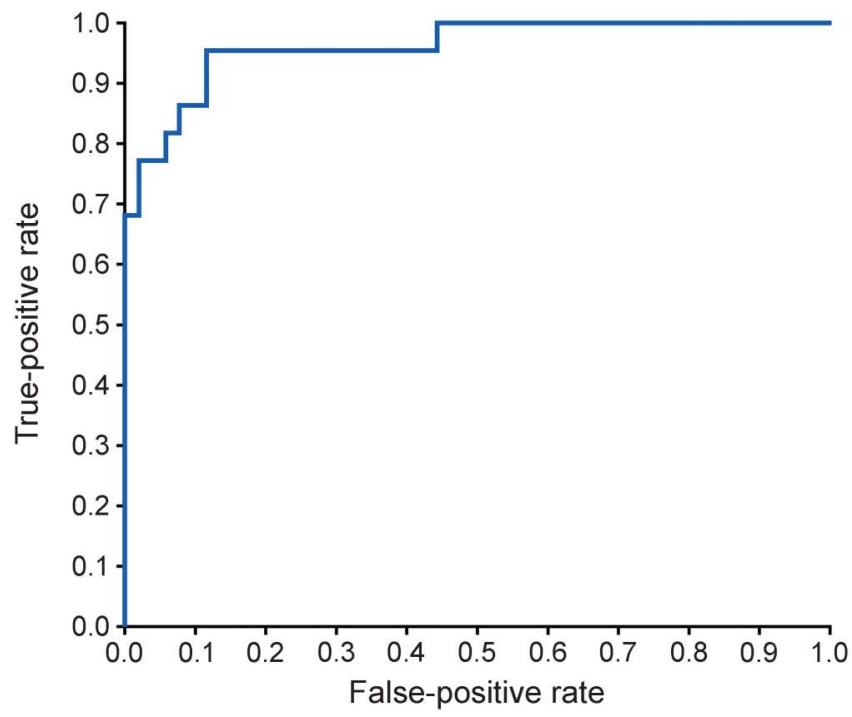

(A) The steps of linear discriminant analysis (LDA) to identify discriminants for Parkinson disease (PD) with dementia (PDD). Two LDA models were used. Model 1 combined age with biochemical measures and led to 14 proteins that along with age resulted in $96 \%$ sensitivity and $89 \%$ specificity (area under the curve $[A U C]=0.9615$ ). Model 2 analyzed only biochemical measures and led to 24 discriminants at $91 \%$ sensitivity and $100 \%$ specificity (AUC $=0.986$ ). A smaller 9-protein (indicated by superscript a in the model 2) panel is illustrated here. This subpanel gave $91 \%$ sensitivity and $90 \%$ specificity (AUC $=0.9143$ ). (B) The receiver operating characteristic $(\mathrm{ROC})$ curve for the model including 14 proteins and age as discriminants is shown here. The curve shows the true-positive rate, or sensitivity, and the false-positive rate, or 1 - specificity, at various confidence thresholds from the LDA model. GF = growth factor; IM = immune modulator; VM = vascular modulator. 
discrimination given that the levels of these proteins differed between disease groups before multiple comparison correction. However, the prediction value was low $(45 \%$ sensitivity and $67 \%$ specificity, AUC $=$ $0.564)$.

Next, we tested whether combining age as a discriminant with biochemical measures could successfully differentiate PDD from PD. In this model, a 14-protein panel (figure 1A) along with age gave $96 \%$ sensitivity and $89 \%$ specificity (AUC = $0.9615)$. Figure $1 \mathrm{~B}$ displays the ROC curve for this model, from which the optimal threshold was chosen in order to maximize sensitivity. Based on current understanding, 7 of these 14 proteins mediate growth and trophic functions (BMP-5, FGF-4, IGF-1, NGF-R, PDGF-AA, PDGF-BB, and SCF).

We then tested a stepwise LDA model in which only biochemical measures were considered as discriminants. This second model selected 24 proteins that identified PDD with $91 \%$ sensitivity and $100 \%$ specificity (AUC $=0.986$ ). The 24-protein panel consisted of 11 chemokines, 5 growth factors, 4 immune modulators, 3 vascular modulators, and $\alpha$-synuclein (figure 1). Among chemokines, 7 belong to the CCL category (CCL13, 17, 18, 19, 20, 21, and 24) and 4 belong to the CXCL category (CXCL1, 7, 10, and 13). Notably, CCL17 (TARC), SCF, and uPAR were selected by both models.

Based on this 24-protein panel finding, we further determined the minimal number of proteins required for obtaining an AUC of 0.90 by entering these proteins into a new stepwise LDA model. As a result, 9 proteins (BLC, BTC, GRO, LIGHT, TARC, CD14, CEACAM-1, ErbB3, and uPAR) were selected that achieved $91 \%$ sensitivity and $90 \%$ specificity (AUC $=0.9143$ ). This panel consisted of chemokines (CXCL1, CXCL13, and CCL17), growth factors (BTC and ErbB3), immune cell modulators (CD14 and LIGHT), and vascular modulators (CEACAM-1 and uPAR).

Correlates of plasma $\alpha$-synuclein. In this cohort, the ageadjusted levels of $\alpha$-synuclein did not differ between the PD and PDD groups (PD: 38,424.546 \pm $1,958.331 \mathrm{pg} / \mathrm{mL}$; PDD: 37,474.561 $\pm 3,057.912$ $\mathrm{pg} / \mathrm{mL} ; p=0.798)$. However, analysis of correlations between the levels of $\alpha$-synuclein and other plasma proteins showed significant positive correlations for 26 proteins (table 2). Among these proteins, the levels of PDGF-BB, TARC, PDGF-AA, and EGF were most highly correlated with $\alpha$-synuclein $(p<0.0003)$. These 4 proteins survived multiple comparison correction using FDR.

Cognitive measures, age, duration, and biochemical correlates. We also determined whether MMSE, CDR,

\begin{tabular}{|c|c|c|}
\hline Table 2 & $\begin{array}{l}\text { Correlation coefficien } \\
\text { that correlated with } p \\
\text { levels }\end{array}$ & $\begin{array}{l}\text { proteins } \\
\text { synuclein }\end{array}$ \\
\hline Protein & $\begin{array}{l}\text { Correlation } \\
\text { coefficient }^{\mathrm{a}}\end{array}$ & $p$ Value $^{b}$ \\
\hline PDGF-BB & 0.535 & 9.03E-7 \\
\hline TARC & 0.516 & $2.0 \mathrm{E}-6$ \\
\hline PDGF-AA & 0.460 & $3.8 \mathrm{E}-5$ \\
\hline EGF & 0.405 & $3.41 E-4$ \\
\hline PDGF-Rb & 0.356 & $0.002^{c}$ \\
\hline MIF & 0.348 & $0.002^{c}$ \\
\hline VEGF-R2 & 0.336 & $0.003^{c}$ \\
\hline MDC & 0.331 & $0.004^{c}$ \\
\hline GRO & 0.328 & $0.004^{c}$ \\
\hline Lipocalin-2 & 0.312 & $0.007^{c}$ \\
\hline ENA-78 & 0.299 & $0.010^{c}$ \\
\hline ICAM-3 & 0.297 & $0.010^{c}$ \\
\hline MPIF-1 & 0.295 & $0.011^{\mathrm{c}}$ \\
\hline IL-29 & 0.282 & $0.015^{c}$ \\
\hline BDNF & 0.281 & $0.015^{c}$ \\
\hline SDF- $1 \alpha$ & 0.274 & $0.018^{c}$ \\
\hline ICAM-1 & 0.265 & $0.022^{c}$ \\
\hline I-TAC & 0.264 & $0.023^{c}$ \\
\hline VEGF & 0.259 & $0.026^{c}$ \\
\hline RANTES & 0.256 & $0.028^{c}$ \\
\hline GCP-2 & 0.255 & $0.028^{c}$ \\
\hline IL-17 & 0.254 & $0.029^{c}$ \\
\hline SCF-R & 0.244 & $0.036^{c}$ \\
\hline IL-17R & 0.240 & $0.039^{c}$ \\
\hline MIP-1 $\beta$ & 0.234 & $0.044^{c}$ \\
\hline IL-1-RI & 0.234 & $0.045^{c}$ \\
\hline
\end{tabular}

${ }^{a}$ Bivariate Pearson correlation coefficient. ${ }^{\mathrm{b}} \mathrm{p}$ Value from 2-tailed correlation analysis.

${ }^{\mathrm{c}}$ Did not survive multiple comparison correction using false discovery rate.

AVLT-A7, age, and disease duration correlated with the protein levels in patients with PD (table 3). Notably, TNF- $\alpha$ and IL-2, which were selected as discriminants in the model including age, showed significant positive correlations with CDR scores $\left(r=0.479, p=3.75 \times 10^{-4}\right.$ for TNF- $\alpha ; r=$ $0.365, p=0.008$ for IL-2). However, after multiple comparison correction only lymphotactin and TNF- $\alpha$ remained significantly correlated with CDR scores. Among 19 proteins that showed significant correlations with age, only TIMP-1 and MIG remained significantly correlated with age after FDR correction $(r=0.409, p=0.0003$ for TIMP$1 ; r=0.397, p=0.0005$ for MIG). The correlations with disease duration did not survive multiple comparison correction. 


\begin{tabular}{|c|c|c|}
\hline Table 3 & \multicolumn{2}{|c|}{$\begin{array}{l}\text { Neuropsychological measures, disease } \\
\text { duration, age, and biochemical } \\
\text { correlates }\end{array}$} \\
\hline Protein & $\begin{array}{l}\text { Correlation } \\
\text { coefficient }^{\mathrm{a}}\end{array}$ & p Value ${ }^{b}$ \\
\hline \multicolumn{3}{|l|}{ MMSE } \\
\hline DR6 & 0.346 & $0.013^{c}$ \\
\hline ENA-78 & -0.330 & $0.018^{c}$ \\
\hline IL-1 $\beta$ & 0.298 & $0.034^{c}$ \\
\hline \multicolumn{3}{|l|}{ AVLT-A7 } \\
\hline MIP-1d & -0.401 & $0.0035^{c}$ \\
\hline MIG & -0.392 & $0.0044^{c}$ \\
\hline LIF & 0.356 & $0.010^{c}$ \\
\hline MCP-1 & -0.354 & $0.011^{c}$ \\
\hline IL-17R & -0.338 & $0.015^{c}$ \\
\hline $\mathrm{MSP} \alpha$ & 0.297 & $0.034^{c}$ \\
\hline IGFBP-6 & -0.282 & $0.045^{c}$ \\
\hline Eotaxin & -0.281 & $0.046^{c}$ \\
\hline Fas & 0.279 & $0.047^{c}$ \\
\hline \multicolumn{3}{|l|}{ Global CDR } \\
\hline Lymphotactin & 0.494 & $2.28 \mathrm{E}-4$ \\
\hline TNF- $\alpha$ & 0.479 & $3.75 E-4$ \\
\hline MCP-3 & 0.446 & $0.001^{c}$ \\
\hline IL-17 & 0.437 & $0.001^{c}$ \\
\hline IL-1 R4 & 0.380 & $0.006^{c}$ \\
\hline IL-2 & 0.365 & $0.008^{c}$ \\
\hline Eotaxin-3 & 0.344 & $0.013^{c}$ \\
\hline MCSF & 0.343 & $0.014^{c}$ \\
\hline MCP-4 & 0.340 & $0.015^{c}$ \\
\hline OPN & 0.311 & $0.026^{c}$ \\
\hline IL-16 & 0.305 & $0.030^{c}$ \\
\hline BDNF & 0.283 & $0.044^{c}$ \\
\hline \multicolumn{3}{|l|}{ Years until PDD } \\
\hline GITR & 0.636 & $0.005^{c}$ \\
\hline ICAM-3 & -0.620 & $0.006^{c}$ \\
\hline IL-1 R4 & 0.617 & $0.006^{c}$ \\
\hline Fas & 0.541 & $0.020^{c}$ \\
\hline BMP-7 & 0.521 & $0.027^{c}$ \\
\hline MDC & -0.497 & $0.036^{c}$ \\
\hline TARC & -0.472 & $0.048^{c}$ \\
\hline \multicolumn{3}{|l|}{ PDD duration } \\
\hline IP-10 & 0.589 & $0.010^{c}$ \\
\hline IL-13 & 0.530 & $0.024^{c}$ \\
\hline TNF- $\alpha$ & -0.512 & $0.030^{c}$ \\
\hline IFN- $\gamma$ & -0.471 & $0.049^{c}$ \\
\hline \multicolumn{3}{|l|}{ Age } \\
\hline TIMP-1 & 0.409 & $2.95 \mathrm{E}-4$ \\
\hline MIG & 0.397 & 4.67E-4 \\
\hline
\end{tabular}

\begin{tabular}{|c|c|c|}
\hline Table 3 & & \\
\hline Protein & $\begin{array}{l}\text { Correlation } \\
\text { coefficient }^{\mathrm{a}}\end{array}$ & $p$ Value $^{b}$ \\
\hline ICAM-3 & 0.369 & $0.001^{c}$ \\
\hline GDF-15 & 0.363 & $0.001^{c}$ \\
\hline MIP-1d & 0.358 & $0.002^{c}$ \\
\hline UPAR & 0.331 & $0.004^{c}$ \\
\hline $1-309$ & 0.318 & $0.006^{c}$ \\
\hline MCP-1 & 0.318 & $0.006^{c}$ \\
\hline PDGF-Rb & 0.311 & $0.007^{c}$ \\
\hline Eotaxin & 0.280 & $0.016^{c}$ \\
\hline$A x I$ & -0.276 & $0.017^{c}$ \\
\hline E-Selectin & 0.276 & $0.017^{c}$ \\
\hline CCL28 & 0.265 & $0.022^{c}$ \\
\hline 6Ckine & 0.264 & $0.023^{c}$ \\
\hline NT-4 & -0.261 & $0.025^{c}$ \\
\hline FGF-4 & -0.251 & $0.031^{c}$ \\
\hline TNF-RII & 0.250 & $0.032^{c}$ \\
\hline PF4 & -0.232 & $0.047^{c}$ \\
\hline IL-1及 & -0.230 & $0.049^{c}$ \\
\hline
\end{tabular}

Abbreviations: AVLT-A7 = Auditory Verbal Learning Test-A7; CDR $=$ Clinical Dementia Rating; MMSE $=$ MiniMental State Examination; PD = Parkinson disease; PDD = Parkinson disease with dementia.

Number of patients included for analysis: MMSE, AVLT-A7, and Global CDR: 51 patients with PD; PD duration and years until PDD: 18 patients with PDD with available disease duration and conversion information; age: 52 patients with $\mathrm{PD}$ and 22 patients with PDD.

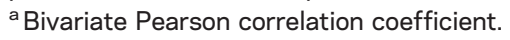

${ }^{\mathrm{b}} \mathrm{p}$ Value from 2-tailed correlation analysis.

${ }^{c}$ Did not survive multiple comparison correction using false discovery rate.

We then determined whether the 14-protein discriminant panel collectively correlated with cognitive measures using multiple variable regression analysis. Overall, MMSE and CDR were each correlated with the panel of 14 protein determinants (MMSE: $R^{2}=0.412, p=0.024$; CDR: $R^{2}=$ $0.542, p=0.0004)$, but AVLT-A7 was not $\left(R^{2}=\right.$ $0.290, p=0.257)$

Correlations between biochemical discriminants. While analyzing the correlations between the levels of each protein in both models, we found that several of these proteins significantly correlated with each other in their plasma concentrations. The majority of the correlations remained significant after multiple comparison correction. In figure 2, an illustration of how the discriminants correlated shows either direct or indirect pairwise associations among proteins. For example, in addition to correlating with each other, PDGF-BB and IL-15 were also correlated with one common protein, IL-2, as well as other proteins. 
Figure 2 Schematic illustration of relationship between individual discriminants

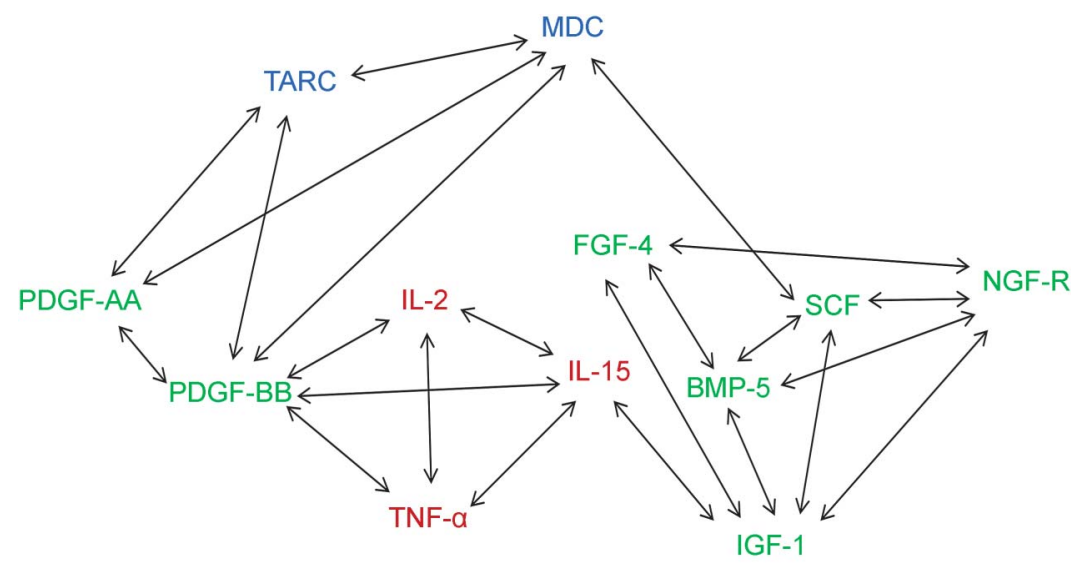

Orphans: UPAR and CXCL16

The model that combined age with biochemical measures gave a 14-protein panel. Among these 14 proteins, 12 of them had significant correlations with various proteins (correlation coefficients are shown in table 4). UPAR and CXCL16 did not correlate with any other proteins. The proteins that were significantly correlated after multiple comparison test are connected with double-headed arrows. Growth/trophic factors are in green, cytokines are in red, and chemokines are in blue.

DISCUSSION This study used a nonbiased approach to evaluate whether plasma levels of 160 immune and trophic factors and the synaptic protein $\alpha$-synuclein could be potential candidates for discriminating PDD from PD. We identified 3 panels of proteins using 2 statistical models, for which age was either included or excluded as a discriminant. In the model considering biochemical factors alone, separate panels consisting of 24 or 9 proteins were identified, giving respective AUCs of 0.986 and 0.9143 . Including age in the discrimination model led to the discovery of a 14-protein panel that could discriminate PDD with $96 \%$ sensitivity and $89 \%$ specificity (AUC $=$ $0.9615)$. The association of the 14-protein panel with cognitive variables was further supported by the results of a regression analysis that showed significant correlation with MMSE and global CDR scores.

Findings from both statistical models demonstrated that chemokines and growth/trophic factors were the major contributors to the discriminant panels. The chemokine family has been previously investigated for cognition-associated markers in PD using other assay platforms. ${ }^{16,19,25,26}$ In a study that analyzed plasma samples for the levels of 4 chemokines (CXCL10, CCL2, CCL11 and CCL24) in 25 normal controls and 40 patients with PD, CXCL10 (IP-10) was identified as the best correlate of the memory score (MMSE) and mental flexibility score (the Frontal Assessment Battery). ${ }^{19}$ IP-10 was also on our 24protein panel.

A recent study that identified 11 analytes that correlated with Dementia Rating Scale-2 (DRS-2) scores in patients with $\mathrm{PD}$ also showed that the majority of selected analytes were chemokines (CXCL1, CXCL5, and CCL 5 or GRO- $\alpha$, ENA78, and RANTES) and growth/survival factors (EGF, HBEGF, PDGF, and SCF). ${ }^{16}$ Among these analytes, EGF levels showed the highest correlation with age-adjusted DRS-2 scores, but as a PDD classifier the maximal accuracy was $79 \%{ }^{16}$ EGF was not identified as a PDD discriminant by either of statistical models in our study. However, we did identify PDGF and SCF in both models and GRO- $\alpha$ in the model excluding age as a discriminant. We also identified additional growth factors (figure 1), suggesting broad involvement of the growth/trophic factor family in PDD. Postmortem human PD brain study has shown deficiency of neurotrophic factors. ${ }^{27}$ However, how changes in brain neurotrophic factors correlate with their levels in the blood remains elusive. Our findings that plasma levels of PDGF-BB, PDGF-AA, and EGF are highly correlated with the plasma $\alpha$-synuclein levels after multiple comparison correction suggest the possibility that the source of interaction is peripheral.

A novel feature of the discriminant panel obtained from both models is the identification of factors crucial to the immune functions of $\mathrm{T}$ cells. For example, IL-2, IL-15, LIGHT, GITR, and IL-21R have specific roles in differentiation and regulation of innate and adaptive immunity of various $T$ lymphocyte subclasses. ${ }^{28-31} \mathrm{PD}$ is associated with $\mathrm{T}$ cell infiltration in the pathology-affected brain regions along with abnormal functions of the subclasses of T cells. ${ }^{32-34}$ Identification of $\mathrm{T}$ cell functional mediators as discriminants of PDD suggests that development of dementia in patients with PD might induce distinct abnormality in the immune system.

Age-associated blood-brain barrier abnormalities and systemic inflammation could contribute to the interplay of peripheral and central inflammation. ${ }^{35,36}$ Older age has been associated with the prediction of dementia in patients with PD. ${ }^{37,38}$ However, age by itself was not sufficient to identify PDD. Rather, our study demonstrated the potential of distinguishing PDD by including age as a discriminant along with biochemical measures; this should be tested further in a larger population-based study. At present, the progress in discovering blood-based biomarkers for PDD is still rather limited. Models that combine biochemical and nonbiochemical measures could be useful for enhancing the accuracy of prediction. Quantitative EEG (QEEG) has recently been shown to be a promising predictor for PDD. ${ }^{12,39}$ Studies that combine QEEG and blood biomarkers could be tested.

This study demonstrated that (1) patients with PDD have changes in plasma proteins that distinguish them from patients with PD; (2) including age as a discriminatory factor led to a panel of 


\begin{tabular}{|c|c|c|}
\hline $\begin{array}{l}\text { Correl } \\
\text { identi }\end{array}$ & \multicolumn{2}{|c|}{$\begin{array}{l}\text { Correlation coefficients between } \\
\text { identified protein discriminants }\end{array}$} \\
\hline Protein pair & $\begin{array}{l}\text { Correlation } \\
\text { coefficient }^{\mathrm{a}}\end{array}$ & p Value ${ }^{b}$ \\
\hline BMP-5-IGF-1 & 0.666 & $\begin{array}{l}9.63 E- \\
11\end{array}$ \\
\hline BMP-5-SCF & 0.625 & $2.58 \mathrm{E}-9$ \\
\hline BMP-5-FGF-4 & 0.587 & $3.81 \mathrm{E}-8$ \\
\hline BMP-5-NGF-R & 0.435 & $1.06 \mathrm{E}-4$ \\
\hline FGF-4-IGF-1 & 0.894 & $\begin{array}{l}7.21 \mathrm{E}- \\
27\end{array}$ \\
\hline FGF-4-NGF-R & 0.814 & $\begin{array}{l}1.18 \mathrm{E}- \\
18\end{array}$ \\
\hline FGF-4-BMP-5 & 0.587 & $3.81 \mathrm{E}-8$ \\
\hline FGF-4-SCF & 0.484 & $1.20 E-5$ \\
\hline FGF-4-IL-15 & 0.229 & $0.050^{c}$ \\
\hline IGF-1-FGF-4 & 0.894 & $\begin{array}{l}7.21 \mathrm{E}- \\
27\end{array}$ \\
\hline IGF-1-NGF-R & 0.850 & $\begin{array}{l}1.08 \mathrm{E}- \\
21\end{array}$ \\
\hline IGF-1-SCF & 0.685 & $\begin{array}{l}1.66 \mathrm{E}- \\
11\end{array}$ \\
\hline IGF-1-BMP-5 & 0.666 & $\begin{array}{l}9.63 E- \\
11\end{array}$ \\
\hline IGF-1-IL-15 & 0.297 & 0.010 \\
\hline IL-2-IL-15 & 0.829 & $\begin{array}{l}8.11 \mathrm{E}- \\
20\end{array}$ \\
\hline IL-2-TNF- $\alpha$ & 0.742 & $\begin{array}{l}4.13 E- \\
14\end{array}$ \\
\hline IL-2-PDGF-BB & 0.612 & $6.79 E-9$ \\
\hline IL-2-TARC & 0.256 & $0.028^{c}$ \\
\hline IL-15-IL-2 & 0.829 & $\begin{array}{l}8.11 \mathrm{E}- \\
20\end{array}$ \\
\hline IL-15-TNF- $\alpha$ & 0.753 & $\begin{array}{l}9.47 \mathrm{E}- \\
15\end{array}$ \\
\hline IL-15-PDGF-BB & 0.560 & $2.13 E-7$ \\
\hline IL-15-IGF-I & 0.297 & 0.010 \\
\hline IL-15-NGF-R & 0.243 & $0.037^{c}$ \\
\hline IL-15-FGF-4 & 0.229 & $0.050^{c}$ \\
\hline MDC-PDGF-AA & 0.424 & $1.69 \mathrm{E}-4$ \\
\hline MDC-TARC & 0.394 & 0.001 \\
\hline MDC-PDGF-BB & 0.338 & 0.003 \\
\hline MDC-SCF & 0.295 & 0.011 \\
\hline MDC-TNF- $\alpha$ & 0.234 & $0.045^{c}$ \\
\hline NGF-R-IGF-1 & 0.850 & $\begin{array}{l}1.08 \mathrm{E}- \\
21\end{array}$ \\
\hline NGF-R-FGF-4 & 0.814 & $\begin{array}{l}1.18 \mathrm{E}- \\
18\end{array}$ \\
\hline NGF-R-BMP-5 & 0.435 & $1.06 \mathrm{E}-4$ \\
\hline NGF-R-SCF & 0.395 & 4.97E-4 \\
\hline NGF-R-IL-15 & 0.243 & $0.037^{c}$ \\
\hline PDGF-AA-MDC & 0.424 & $1.69 \mathrm{E}-4$ \\
\hline PDGF-AA-PDGF-BB & 0.397 & 4.57E-4 \\
\hline PDGF-AA-TARC & 0.389 & 0.001 \\
\hline
\end{tabular}

\begin{tabular}{|c|c|c|}
\hline Continued & & \\
\hline Protein pair & $\begin{array}{l}\text { Correlation } \\
\text { coefficient }^{\mathrm{a}}\end{array}$ & $p$ Value $^{b}$ \\
\hline PDGF-BB-TNF- $\alpha$ & 0.612 & $6.74 \mathrm{E}-9$ \\
\hline PDGF-BB-IL-2 & 0.612 & $6.79 \mathrm{E}-9$ \\
\hline PDGF-BB-IL-15 & 0.560 & 2.13E-7 \\
\hline PDGF-BB-PDGF-AA & 0.397 & 4.57E-4 \\
\hline PDGF-BB-TARC & 0.361 & 0.002 \\
\hline PDGF-BB-MDC & 0.338 & 0.003 \\
\hline SCF-IGF-1 & 0.685 & $\begin{array}{l}1.66 \mathrm{E}- \\
11\end{array}$ \\
\hline SCF-BMP-5 & 0.625 & $2.58 \mathrm{E}-9$ \\
\hline SCF-FGF-4 & 0.484 & $1.20 \mathrm{E}-5$ \\
\hline SCF-NGF-R & 0.395 & 4.97E-4 \\
\hline SCF-MDC & 0.295 & 0.011 \\
\hline TARC-MDC & 0.394 & 0.001 \\
\hline TARC-PDGF-AA & 0.389 & 0.001 \\
\hline TARC-PDGF-BB & 0.361 & 0.002 \\
\hline TARC-IL-2 & 0.256 & $0.028^{c}$ \\
\hline TARC-TNF- $\alpha$ & 0.230 & $0.048^{c}$ \\
\hline TNF- $\alpha-I L-15$ & 0.753 & $\begin{array}{l}9.47 \mathrm{E}- \\
15\end{array}$ \\
\hline TNF- $\alpha-I L-2$ & 0.742 & $\begin{array}{l}4.13 \mathrm{E}- \\
14\end{array}$ \\
\hline TNF- $\alpha$-PDGF-BB & 0.612 & $6.74 \mathrm{E}-9$ \\
\hline TNF- $\alpha-M D C$ & 0.234 & $0.045^{c}$ \\
\hline TNF- $\alpha-$ TARC & 0.230 & $0.048^{c}$ \\
\hline
\end{tabular}

${ }^{a}$ Bivariate Pearson correlation coefficient.

${ }^{\mathrm{b}} \mathrm{p}$ Value from 2-tailed correlation analysis.

${ }^{\mathrm{c}}$ Did not survive multiple comparison correction using false discovery rate.

biochemical measures with good sensitivity and specificity for distinguishing PDD from PD; and (3) proteomic platforms such as Quantibody arrays are suitable for nonbiased blood-based discovery study of PDD biomarkers. Our findings demonstrated that converging mediators from immune and trophic pathways brought discriminatory power to the cognitive impairment in patients with PD. Because this is a discovery-based study, replication in a populationbased longitudinal study will be needed.

\section{AUTHOR AFFILIATIONS}

From the Neuroregeneration Laboratory (L.-F.L., C.T.S.), Neuroinflammation Laboratory (D.G.W.), Cleo Roberts Center for Clinical Research (K.J.D., C.B., M.N.S.), and Thomas Christopher Center for Parkinson's Research (H.A.S.), Banner Sun Health Research Institute, Sun City, AZ; Biomathemetician Core (N.L.S., K.C.), Banner Alzheimer's Institute, Phoenix, AZ; and Mayo Clinic Arizona (J.N.C., E.D.-D., C.H.A.), Scottsdale, AZ. L.-F.L., C.T.S., and D.G.W. are currently affiliated with the ASU-Banner Neurodegenerative Disease Research Center, Biodesign Institute, Arizona State University, Tempe, AZ. M.N.S. is currently affiliated with the Alzheimer's and Memory Disorders Division, Barrow Neurological Institute, Phoenix, AZ. H.A.S. is currently affiliated with 
the Lonnie and Muhammad Ali Movement Disorder Center, Barrow Neurological Institute, Phoenix, AZ.

\section{AUTHOR CONTRIBUTIONS}

L.F.-L. conceptualized and designed the study, interpreted the data, and wrote the manuscript. C.T.S. processed the samples and performed analysis. N.L.S. performed statistical analysis. K.C. interpreted bioinformatics data. D.G.W. contributed to discussion and edited the manuscript. K.J.D. maintained and organized the database for the study. H.A.S., J.N.C., C.H.A., E.D.-D., C.B., and M.N.S. determined clinical criteria and diagnosed patients for this study.

\section{ACKNOWLEDGMENT}

Participants in this study were enrolled at the Cleo Roberts Center for Clinical Research. The authors thank the Arizona Study of Aging and Neurodegenerative Disorders, with special thanks to Mrs. Carolyn Liebsack and Amy Rangel. The authors also thank Dr. Lue's staff members, Dr. Guna Sherlin Moses, Mr. Jason Zhong, Mrs. Casandra Andrade, and Mr. Kevin Tran.

\section{STUDY FUNDING}

This research project was funded by the Michael J. Fox Foundation for Parkinson's Research (to L.-F.L.). Additional funding support for data analysis was provided by Arizona State (to K.C.).

\section{DISCLOSURE}

L.-F. Lue received research support from Arizona Alzheimer's Consortium and Michael J. Fox Foundation. C.T. Schmitz and N.L. Snyder report no disclosures. K. Chen is an academic editor for PLOS ONE and Editor-in-Chief for Neuroscience and Biomedical Engineering, is employed by Banner Alzheimer's Institute, and received research support from NIMH, NIA, state of Arizona, and Banner Alzheimer's Foundation. D.G. Walker is on the NIH study section CNBT and Veterans Administration NURD, received travel funding and/or speaker honoraria from Upsher Smith Laboratories, is on the editorial board for Current Alzheimer's Research, and received research support from NIH and Michael J. Fox Foundation for Parkinson's Research. K.J. Davis reports no disclosures. C. Belden is employed by Banner Health Corporation, is a rater on clinical trials at the Banner Sun Health Research Institute, and received research support from NINDS, NIA, Arizona Department of Health Services, Arizona Biomedical Research Commission, and Michael J. Fox Foundation for Parkinson's Research. J.N. Caviness is an editorial board member for Tremor and Other Hyperkinetic Movement Disorders, has consulted for Teva, and received research support from U24 Resource for Parkinson's Research and Michael J. Fox Foundation for Parkinson's Research. E. Driver-Dunckley reports no disclosures. C.H. Adler received travel funding and/or speaker honoraria from Movement Disorder Society; received publishing royalties from Humana Press; has consulted for Allergan, Inc, Acadia, Impax, Ipsen, Lilly, Lundbeck, Merz Pharmaceuticals, and Teva; and received research support from Avid Radiopharmaceuticals, Department of Defense, NIH/NINDS, and Michael J. Fox Foundation for Parkinson's Disease Research. M.N. Sabbagh gives lectures on wellness with compensation in senior living communities; is on the editorial board for Journal of Alzheimer's Disease, BMC Neurology, Alzheimer's Disease and Associated Disorders, Current Alzheimer's Research, and American Journal of Alzheimer's and Dementia; receives publishing royalties from Wiley, TenSpeed, and Wiley Oxford; has consulted for Avid Pharmaceuticals, Biogen, FORUM Pharmaceuticals, Fujirebio Diagnostics, Inc, Lilly Pharmaceuticals, Primal Imaging, Transtech Pharma Inc, and vTv Therapeutics; received research support from AstraZeneca, Avid Pharmaceuticals, Functional Neuromodulation, Genentech Inc, Lilly Pharmaceuticals, Merck \& Co Inc, Navidea, Neuronix, Roche Diagnostics Corporation, Takeda, NIA, ABRC Down Syndrome, The Alzheimer's Disease Cooperative study, and ADNI; and holds stock/stock options in Brain Health, Inc, Muses Labs, Inc, and Wasabia/Versanum. H.A. Shill has consulted for Navidea Pharmaceuticals and received research support from Adamas, Cynapsus, Kyowa, US World Meds and Avid, NIH, Michael J. Fox Foundation for Parkinson Research, International Essential Tremor Foundation, Sun Health Foundation, and Consolidated Anti-Aging Foundation. Go to Neurology.org/nn for full disclosure forms.

Received April 28, 2015. Accepted in final form October 21, 2015.

\section{REFERENCES}

1. Metzler-Baddeley C. A review of cognitive impairments in dementia with Lewy bodies relative to Alzheimer's disease and Parkinson's disease with dementia. Cortex 2007;43: 583-600.

2. Galvin JE, Pollack J, Morris JC. Clinical phenotype of Parkinson disease dementia. Neurology 2006;67: 1605-1611.

3. Aarsland D, Zaccai J, Brayne C. A systematic review of prevalence studies of dementia in Parkinson's disease. Mov Disord 2005;20:1255-1263.

4. Hobson P, Meara J. Risk and incidence of dementia in a cohort of older subjects with Parkinson's disease in the United Kingdom. Mov Disord 2004;19:1043-1049.

5. Aarsland D, Andersen K, Larsen JP, et al. Prevalence and characteristics of dementia in Parkinson disease: an 8-year prospective study. Arch Neurol 2003;60:387-392.

6. Hely MA, Reid WG, Adena MA, et al. The Sydney multicenter study of Parkinson's disease: the inevitability of dementia at 20 years. Mov Disord 2008;23:837-844.

7. Xu J, Gong DD, Man CF, et al. Parkinson's disease and risk of mortality: meta-analysis and systematic review. Acta Neurol Scand 2014;129:71-79.

8. Marras C, McDermott MP, Rochon PA, et al. Predictors of deterioration in health-related quality of life in Parkinson's disease: results from the DATATOP trial. Mov Disord 2008;23:653-659.

9. Vossius C, Larsen JP, Janvin C, et al. The economic impact of cognitive impairment in Parkinson's disease. Mov Disord 2011;26:1541-1544.

10. Leroi I, McDonald K, Pantula H, et al. Cognitive impairment in Parkinson disease: impact on quality of life, disability, and caregiver burden. J Geriatr Psychiatry Neurol 2012;25:208-214.

11. Koller D, Schon G, Schafer I, et al. Multimorbidity and long-term care dependency - a five-year follow-up. BMC Geriatr 2014;14:70.

12. Caviness JN, Lue L, Adler CH, et al. Parkinson's disease dementia and potential therapeutic strategies. CNS Neurosci Ther 2011;17:32-44.

13. Troster AI. Neuropsychological characteristics of dementia with Lewy bodies and Parkinson's disease with dementia: differentiation, early detection, and implications for "mild cognitive impairment" and biomarkers. Neuropsychol Rev 2008;18:103-119.

14. Poewe W, Gauthier S, Aarsland D, et al. Diagnosis and management of Parkinson's disease dementia. Int J Clin Pract 2008;62:1581-1587.

15. Henchcliffe C, Dodel R, Beal MF. Biomarkers of Parkinson's disease and Dementia with Lewy bodies. Prog Neurobiol 2011;95:601-613.

16. Chen-Plotkin AS, Hu WT, Siderowf A, et al. Plasma epidermal growth factor levels predict cognitive decline in Parkinson disease. Ann Neurol 2011;69:655-663.

17. Ma J, Jiang $\mathrm{Q}, \mathrm{Xu}$ J, et al. Plasma insulin-like growth factor 1 is associated with cognitive impairment in Parkinson's disease. Dement Geriatr Cogn Disord 2015;93:251-256.

18. Pellecchia MT, Santangelo G, Picillo M, et al. Serum epidermal growth factor predicts cognitive functions in early, 
drug-naive Parkinson's disease patients. J Neurol 2013; 260:438-444

19. Rocha NP, Scalzo PL, Barbosa IG, et al. Cognitive status correlates with CXCL10/IP-10 levels in Parkinson's disease. Parkinsons Dis 2014;2014:903796.

20. Menza M, Dobkin RD, Marin H, et al. The role of inflammatory cytokines in cognition and other non-motor symptoms of Parkinson's disease. Psychosomatics 2010;51:474-479.

21. Chahine LM, Stern MB, Chen-Plotkin A. Blood-based biomarkers for Parkinson's disease. Parkinsonism Relat Disord 2014;20(suppl 1):S99-S103.

22. Beach TG, Sue LI, Walker DG, et al. The Sun Health Research Institute Brain Donation Program: description and experience, 1987-2007. Cell Tissue Bank 2008;9:229-245.

23. Caviness JN, Driver-Dunckley E, Connor DJ, et al. Defining mild cognitive impairment in Parkinson's disease. Mov Disord 2007;22:1272-1277.

24. Marek K, Jennings D, Lasch S, et al. The Parkinson Progression Marker Initiative (PPMI). Prog Neurobiol 2011; 95:629-635.

25. Scalzo P, de Miranda AS, Guerra Amaral DC, et al. Serum levels of chemokines in Parkinson's disease. Neuroimmunomodulation 2011;18:240-244.

26. Reale M, Iarlori C, Thomas A, et al. Peripheral cytokines profile in Parkinson's disease. Brain Behav Immun 2009; 23:55-63.

27. Nagatsu T, Sawada M. Biochemistry of postmortem brains in Parkinson's disease: historical overview and future prospects. J Neural Transm Suppl 2007;113-120.

28. Nocentini G, Riccardi C. GITR: a modulator of immune response and inflammation. Adv Exp Med Biol 2009;647: 156-173.

29. Tangye SG. Advances in IL-21 biology—enhancing our understanding of human disease. Curr Opin Immunol 2015;34:107-115.
30. Wang Y, Zhu M, Miller M, et al. Immunoregulation by tumor necrosis factor superfamily member LIGHT. Immunol Rev 2009;229:232-243.

31. Zou T, Satake A, Corbo-Rodgers E, et al. Cutting edge: IL-2 signals determine the degree of TCR signaling necessary to support regulatory $\mathrm{T}$ cell proliferation in vivo. J Immunol 2012;189:28-32.

32. Saunders JA, Estes KA, Kosloski LM, et al. CD4+ regulatory and effector/memory $\mathrm{T}$ cell subsets profile motor dysfunction in Parkinson's disease. J Neuroimmune Pharmacol 2012;7:927-938.

33. Cao JJ, Li KS, Shen YQ. Activated immune cells in Parkinson's disease. J Neuroimmune Pharmacol 2011;6: 323-329.

34. Baba Y, Kuroiwa A, Uitti RJ, et al. Alterations of T-lymphocyte populations in Parkinson disease. Parkinsonism Relat Disord 2005;11:493-498.

35. Collins LM, Toulouse A, Connor TJ, et al. Contributions of central and systemic inflammation to the pathophysiology of Parkinson's disease. Neuropharmacology 2012;62: 2154-2168.

36. Su X, Federoff HJ. Immune responses in Parkinson's disease: interplay between central and peripheral immune systems. Biomed Res Int 2014;2014:275178.

37. Anang JB, Gagnon JF, Bertrand JA, et al. Predictors of dementia in Parkinson disease: a prospective cohort study. Neurology 2014;83:1253-1260.

38. Zhu K, van Hilten JJ, Marinus J. Predictors of dementia in Parkinson's disease; findings from a 5-year prospective study using the SCOPA-COG. Parkinsonism Relat Disord 2014;20:980-985.

39. Caviness JN, Hentz JG, Belden CM, et al. Longitudinal EEG changes correlate with cognitive measure deterioration in Parkinson's disease. J Parkinsons Dis 2015;5: $117-124$ 


\section{Neurology ${ }^{\odot}$ \\ Neuroimmunology \& Neuroinflammation}

Converging mediators from immune and trophic pathways to identify Parkinson disease dementia

Lih-Fen Lue, Christopher T. Schmitz, Noelle L. Snyder, et al.

Neurol Neuroimmunol Neuroinflamm 2016;3;

DOI 10.1212/NXI.0000000000000193

This information is current as of January 27, 2016

Neurol Neuroimmunol Neuroinflamm is an official journal of the American Academy of Neurology.

Published since April 2014, it is an open-access, online-only, continuous publication journal. Copyright $\odot$ 2016 American Academy of Neurology. All rights reserved. Online ISSN: 2332-7812.

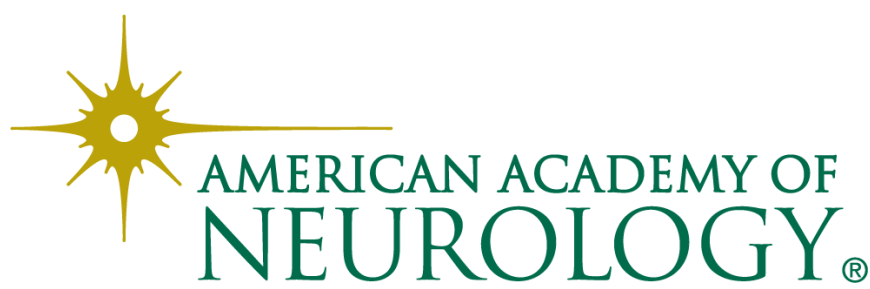




\section{Updated Information \& Services}

References

Subspecialty Collections

Permissions \& Licensing

Reprints including high resolution figures, can be found at:

http://nn.neurology.org/content/3/1/e193.full.html

This article cites 38 articles, 1 of which you can access for free at: http://nn.neurology.org/content/3/1/e193.full.html\#\#ref-list-1

This article, along with others on similar topics, appears in the following collection(s):

\section{Class III}

http://nn.neurology.org//cgi/collection/class_iii

Clinical neurology examination

http://nn.neurology.org//cgi/collection/clinical_neurology_examination

\section{Parkinson's disease with dementia}

http://nn.neurology.org//cgi/collection/parkinsons_disease_with_deme ntia

\section{Parkinson's disease/Parkinsonism}

http://nn.neurology.org//cgi/collection/parkinsons_disease_parkinsonis $\mathrm{m}$

Information about reproducing this article in parts (figures,tables) or in its entirety can be found online at:

http://nn.neurology.org/misc/about.xhtml\#permissions

Information about ordering reprints can be found online:

http://nn.neurology.org/misc/addir.xhtml\#reprintsus

Neurol Neuroimmunol Neuroinflamm is an official journal of the American Academy of Neurology.

Published since April 2014, it is an open-access, online-only, continuous publication journal. Copyright $\odot$ 2016 American Academy of Neurology. All rights reserved. Online ISSN: 2332-7812.

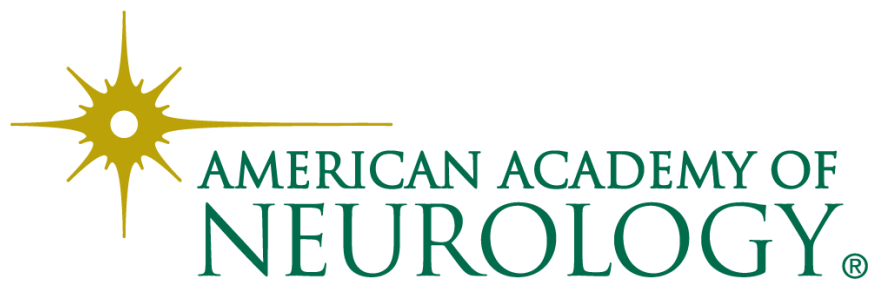

